\title{
Measuring the health impact of Universal Basic Income as an upstream intervention: Holistic trial design that captures stress reduction is essential
}

\begin{abstract}
In the context of the UK Government's 'prevention agenda', Laura Webber and colleagues have called for a 'health in all policies' approach. Universal Basic Income (UBI) is a system of cash transfers to citizens and recent research suggests it may have a significant impact on health, including via an underexplored role in reduced stress. However, debate has been influenced by a recent Finnish trial of a policy with similarities to UBI. This was reported as a failure due to a policy objective of reducing unemployment, despite demonstrating significant benefits to wellbeing. In this article, we advance this debate by exploring the current evidence and proposing a practical way forward. We propose a need to refocus evidence collection in UBI trials on improved health - via reduced stress - to provide policymakers with the means of producing an accurate cost-benefit analysis. We argue that previous trials have either not reflected likely UBI policy or have not measured a sufficient range of impacts to enable accurate analysis of its cost-benefit. We contend that interdisciplinary work is needed in order to establish trials that observe key factors driving the social health gradient. Finally, we argue that statistical modelling is needed to extrapolate short-term findings to long-term population-level outcomes. One implication is that substantial allocation of resource is required from Government and/or major research funders. On the other hand, this presents an opportunity to pioneer an interdisciplinary approach resulting in joined-up evidence and policy for UBI and 'upstream' interventions.
\end{abstract}

Keywords: Universal Basic Income; stress; public health; socioeconomic factors

\section{Key messages}

1. Existing Universal Basic Income trial designs have not enabled accurate assessment of the policy

2. Interdisciplinarity is needed in trials to observe key factors driving the social health gradient

3. Statistical modelling is essential to produce population-level evidence for policy development

4. Financial resource must be directed to establishing more thorough and evidence-based trials

\section{Introduction}

The UK Government has recently developed a Green Paper on health advancing a 'prevention agenda' (Department of Health and Social Care 2019). With concern about the NHS being understood as the 'National Hospital Service' (see Department of Health and Social Care and Hancock 2018; Department of Health and Social Care 2018), there is an emerging commitment to promote action conducive to avoidance of ill-health. In that context, Laura Webber and colleagues (2018) have called for a 'health in all policies' approach grounded in 'upstream interventions'. We (Johnson and Johnson 2019; Johnson, Geyer and Degerman 2019) recently cited the prospective value of Universal Basic Income (UBI) to this end, arguing that its prospective effect in mitigating social sources of stress provides a qualitative shift in justification of the policy toward those in, as well as out of, work. Such an intervention offers the possibility of dealing with the crisis in stress-related ill-health that imposes significant costs on the NHS and wider society. In part because of this research (see Standing 2019, 17-19), the UK Labour Party committed to trialling UBI in such cities as Liverpool and Sheffield in its 2019 Manifesto (Labour Party 2019, 60; Press Association 
2019). In the wake of the Conservative Party's success in the 2019 General Election, Hull City Council has sought permission to conduct a trial of UBI (Halliday 2019).

However, in 2018, a trial of a system with similarities to UBI in Finland was not extended beyond two years, despite calls from the nation's social security agency to do so (Henley 2018). Reporting of this focused on its 'failure' to increase employment, despite improved wellbeing for participants (Henley and agencies 2019, Pohjanpalo 2019). This perceived failure resulted from narrow policy objectives within the centre-right Government that focused solely on reducing the unemployment rate (Valero 2019). Payments were given only to unemployed people and at a rate that was only around $€ 50$ above the previous benefit. Little change to the unemployment rate in a system of payments to all citizens would actually have the potential to counter criticism of UBI as likely reducing incentive to work (Gibson, Hearty and Craig 2018, 100). But the effect of evaluating UBI against a requirement to increase employment has been to cloud interest in it as a policy that addresses challenges to wellbeing. Our contention is that wellbeing - in particular UBI's potential effect on health via stress - is crucial to the social and economic value of UBI as a policy. If policymakers are to be equipped with the means of calculating the cost-benefit of UBI through its impact on all in society, not solely those who are unemployed, trials that take proper account of populationlevel wellbeing are essential.

While the BMJ has called for a trial on health grounds (Painter 2016), and while trials of UBI have indicated self-reported reductions in stress (Kangas, et al. 2019, 30), existing research has failed to measure psychobiological stress in ways that establish UBI's value as an upstream health intervention. This is because all measures of stress are subject to biases in interpretation, especially given the influence of factors like physical activity on cortisol levels (Gerber, et al. 2012). In the case of self-reported psychological stress, there are also challenges in subjective reporting (Brant, et al. 2010; Epel, et al. 2018, 4). All have value in predicting future health outcomes (Epel, et al. 2018, 38-39), but physiological stress, in particular, has been studied in ways that enable predictive modelling for particular conditions and overall mortality (Kumari, et al. 2011). In this analysis, we highlight deficits in trials and present recommendations for future research.

\section{UBI and health}

UBI is a system of universal cash transfers to (adult) citizens that is typically presented as an alternative reduced to need-based welfare systems. It differs starkly from Universal Credit, which is currently being introduced in the UK to replace a number of means-tested benefits and which is tapered down as recipients enter work and earn above a set threshold (Government Digital Service 2014). UBI is paid to all regardless of means or needs, though there is debate over whether it should be conditional on good citizenly behaviour (participation in voting, avoidance of crime, etc.). Historically, it has been justified by those on the left and right variously as a means of promoting citizens' rights (Pettit 2008) within a state (see discussion in Ferry 1995), increasing efficiency in welfare systems (Gordon 2014) and promoting growth (Sheahan 2003). Because UBI has been seen as an economic instrument, the notion of deploying UBI specifically for reasons of public health, and grounding those reasons in the medical literature, marks a key development within the field.

Trials of programmes that resemble UBI have often noted an effect on health (Gibson, Hearty and Craig 2018; Haagh and Rohregger 2019). The Canadian case of Mincome, in Manitoba, which provided an unconditional payment to lower income households (an income guarantee similar to negative income taxation), established a series of impacts, such as adult mental 
health and hospital admissions (Forget 2011). The US case of Gary Indiana, in which low income families received a minimum income guarantee, demonstrated an impact on birth weight (Kehrer and Wohlin 1979). These schemes are in no substantive way comparable to the forms of UBI proposed for the UK because they are targeted at low income groups in which poverty is a significant driver of ill-health. Indeed, initial socioeconomic status (SES) was shown to be the key explanatory factor of obesity in the US case of Tribal Casino Cash Transfers, in which Indigenous Americans receive twice annual taxable cash payments (Akee, et al. 2013). Such studies suggest potential impact on health from those forms of UBI that increase income among those with low income, but they have neither been designed in such a way as to map health impact via reduction in social sources of stress nor to evaluate impact on whole populations.

Indeed, in general, few have either advanced health as a primary or key justification for UBI or designed evaluations of trials in such a way as to measure effect reliably and holistically. This inconsistency may be because proponents assume an effect, because they believe health to be an ancillary concern or because the means by which to understand and assess that effect are complex and demand methodological precision. As Gibson, Heart and Craig $(2018,11)$ note,

A number of studies reported modest to strong positive effects on a range of health outcomes, including low birthweight, adult and child mental health, service use, and diet. Improved parenting quality and reduced financial strain were among the suggested mechanisms underlying some of these improvements. These effects were less consistent than those for labour market outcomes and educational participation, possibly because the outcome measures or the samples included in the analyses differed.

The possibility of an assumption of an effect is apparent in Richardson, et al.'s $(2018,4)$ model examining the potential impact of income-based policies on health inequalities. This model assumes a causal, linear correlation between income and mortality, in which an increase in income will cause a decrease in mortality. Again, this assumption needs clarification.

\section{UBI as a 'health in all policies' upstream intervention}

UBI offers the capacity to deal with disincentives to healthy behaviour inherent in needs- and means-based welfare systems (see Johnson and Spring 2018). People no longer face costs for being active and making health-promoting decisions, such as avoiding opioid painkillers that are often seen as indicators of incapacity by fitness for work benefits assessments (Johnson, Geyer and Degerman 2019).

However, as Johnson and Johnson's (2018) review indicates, UBI's larger impact may lie in its prospective contribution to dealing with Britain's crisis of stress. This crisis was responsible for ' $44 \%$ of all work related ill health cases and $57 \%$ of all working days lost due to ill health' in 2017/18 (Health and Safety Executive 2018, 2), up from $37 \%$ and $45 \%$ in 2015/16 (Health and Safety Executive 2016). Meanwhile, in 2010/11, more than a quarter (around 15 million people) of the population of England had at least one long-term, stressrelated chronic health conditions such as heart disease, stroke, cancer, type 2 diabetes, arthritis and depression (Department of Health 2012). 
Stress is an evolutionary adaptation to enable humans to respond to short-term threats to homeostasis. Perception of threat triggers a cascade of biological changes that prime the body to respond to physical and existential harm, leading to 'increased cardiovascular tone, respiratory rate, and intermediate metabolism, along with inhibition of general vegetative functions such as feeding, digestion, growth, reproduction' (Smith and Vale 2006, 383; see also, Henderson and Baum 2004).

While this serves us well in dealing with mortal threats during times of war and natural disaster, we find that there are socio-economic circumstances that prime us for stress unnecessarily. Research suggests that hierarchical organisational models, in particular, create forms of what republican political theorists have termed domination: the capacity for individuals to make arbitrary decisions that affect others without reference to those individuals' interests.

This concept of domination refers to the possibility of harm being inflicted, rather than the harm itself. In this regard, it refers to those sources of unpredictability that stem from the actions of other human beings. The mere possibility of individuals being subject to arbitrary decisions leaves them in a long-term condition of preparedness for threat - that is to say, long-term stressed by virtue of social unpredictability. Such an account is compatible with those that focus solely on resource scarcity insofar as domination is the threat of the removal of means of subsistence (i.e. through termination of employment). People's exposure to domination increases as their resource-base decreases, meaning that those at the bottom of hierarchies are not just less wealthy than those above them, they are significantly more threatened by the arbitrary decisions made by their superiors. Poverty is a cause of ill-health, but it is not the only cause.

Domination does not refer to natural environmental unpredictability or freak accidents in which, without malice aforethought, an individual inflicts harm on another. While UBI might help us to deal with social sources of resolving the consequences of non-human or accidental actions by granting individuals resources by which to repair damage to themselves or their property, the primary source of unpredictability we suggest it mitigates is one in which, by virtue of power imbalances, individuals are subject to social arbitrariness.

Johnson and Johnson's (2018) review of the endocrinological and immunological literature suggests that such a condition both decreases normal immune function and increases autoimmunity, contributing to the physical ill-health concomitant to the mental health crisis. This is borne out in the Whitehall II Study of Civil Servants, which demonstrates that as individuals occupy lower positions in the hierarchy, they experience increased stress-related ill-health, irrespective of their objective, absolute poverty. Further complicating Richardson et al.'s (2018) assumptions, Tang, et al (2016). showed that the gradient was compounded by individuals' perceived position in their perceived hierarchy.

While the impact of UBI on health in work is Johnson and Johnson's (2018) novel contribution, its relationship with welfare reform is also apparent. At present, the UK's needs- and means-based system renders individuals subject to decisions that are imposed upon them, apparently arbitrarily, by those above them in the welfare bureaucracy. The reasons for those decisions are seldom justified with regard to the interests of recipients and their consequences in terms of health are profound, as the United Nation's Special Rapporteur's report on poverty illustrates (Alston 2018). 
In this social context, Johnson and Johnson argue that, if sufficiently generous to satisfy basic needs, UBI gives people the ability to resist (i.e. by feeling protected from demeaning demands) or leave (i.e. by resigning) conditions of domination, thus freeing them from stress. We argue that trials now need to be designed to measure stress as both a psychological and, importantly, biological phenomenon.

\section{Discussion: Dealing with methodological deficits}

The Whitehall II study provides a methodological blueprint for this purpose. The model emphasises the need to analyse hormonal (particularly cortisol) patterns as well as ambulatory blood pressure and heart rate to create a complete overview of physiological stress levels (Marmot and Steptoe 2008). Present studies of UBI do not follow that model.

In the first instance, some trials, such as that in Finland, focus on self-reported psychological stress. The literature demonstrates that the relationship between this and biological stress is not necessarily straightforward (Epel, et al. 2018, 169). For example, individuals may either not perceive their biological stress response accurately or self-report it differently for a range of social reasons (Simpson, et al. 2008). This is indicated by studies that find no significant association between biological stress and mood (Chida and Steptoe 2009). However, selfreported measures should not be discarded, and play a role in establishing impact on areas such as mental health and quality of life (Lombardo, et al. 2018). Rather, a cluster of measures, both psychological (phenomenological) and biological (biomarkers), should be employed. We do not suggest that health outcomes have not been measured. Rather, we simply argue that the studies in which data has been gathered are not representative of the prospective UBI programmes we would encounter in the UK and that they have failed reliably to measure all of the pathways to health impact. Each measure furthers our understanding of the drivers and markers of stress-related ill-health and provides greater potential for predictive modelling of outcomes.

In the second instance, even those trials that do measure biological markers do so inaccurately. This is apparent in Johannes Haushofer and Jeremy Shapiro's (2016) evaluation of a trial of unconditional cash transfers to low-income household units in Kenya. Their research appears to demonstrate that, while there was a substantial impact of the transfers on subjective psychological measures of wellbeing, there was no overall average reduction in cortisol levels in the single measures taken before and after intervention. However, cortisol levels were significantly lower when transfers were made to the wife rather than husband, when a lump-sum rather than monthly payment was given and when it was large rather than small (Haushofer and Shapiro 2018).

While this may seem to challenge the justification for including biological measures of stress in trials of UBI, there are two significant drivers for these results.

First, interventions at an overall, average level failed to challenge the underlying structural reasons for stress within the communities. Payments to women that were intended to challenge control of wealth by men may have been balanced out by its entrenchment within the group in which transfers were made to men. Indeed, the control of wealth by one head of a household runs counter to the principles of Universal Basic Income, in which selfdetermination and financial security is guaranteed by payment to each and every citizen.

Second, as Haushofer and Shapiro acknowledge, cortisol levels vary substantially across the day, rising sharply in the morning (the cortisol awakening response) and declining across the 
day, as well as being affected by 'food and drink, alcohol and nicotine, medications, and strenuous physical exercise' (Haushofer and Shapiro 2018, 11). While the authors obtained a 'clean' average through OLS regression to control for the influence of the above factors, this ignored several key factors.

Unfortunately, overall levels of cortisol are a poor predictor of disease risk. Rather, it is patterns across the day (and between days) that are an indicator of both future likelihood of ill-health and hierarchically-driven stress. Cortisol awakening response (cortisol level on waking followed by a rise that reaches a peak after 30 minutes) was correlated in Whitehall II both with subjective stress levels and lower socioeconomic position (and, interestingly, gender) which correlated with poorer health outcomes in general (Marmot and Steptoe 2008). A more recent study has suggested that a 'flatter slope' of decline in cortisol across the day, rather than heightened cortisol awakening response, is associated specifically with cardiovascular mortality (Kumari, et al. 2011). Biological measures should not, though, be limited solely to cortisol. Others employed by Whitehall II - such as ambulatory blood pressure and markers of chronic inflammation, like C-reactive protein, fibrinogen and interleukin 6 (IL-6) (Marmot and Steptoe 2008) - are also strong candidates for inclusion in pilots.

UBI's core value in this context lies in promoting autonomy for each citizen and by challenging hierarchies associated with the health gradient in whatever form they are constituted (households, organisations, classes). This prospective benefit applies even to those relatively removed from absolute poverty. Haushofer and Shapiro's interventions targeted only a random selection of 'poor' households, with 'spillover' effects on some neighbouring households. Rather than promoting a flattening of hierarchy and individual autonomy, the intervention may simply have reshaped particular relationships and entrenched relative poverty among those not selected. Ultimately, the study measured only effects on those raised out of absolute poverty (and those at the sharp end of this dynamic who were not selected for payment), rather than others in hierarchies associated with poorer health outcomes, but not in absolute poverty.

Haushofer and Shapiro's study is a step forward and a serious attempt to demonstrate the influence that something approximating UBI might have on biological markers of stress. The differences between group designs, notably the impact of gender, point to areas for follow up.

However, a different approach is required if we are to build upon the evidence of previous studies and develop a trial aimed specifically at measuring public health impact. First and foremost, any trial of UBI must be concerned with payments to individuals. Second, we must follow Whitehall II and recent studies that have built on its findings and measure biological stress more effectively. This includes through measurement of diurnal patterns of cortisol, as well as other indicators such as ambulatory blood pressure, heart rate and markers of chronic inflammation. This more holistic and contextualised approach should be supported by psychological, self-reported measures.

After more than thirty years, Whitehall II's data continues to reveal relationships between stress and health that suggest parameters for trials of UBI. Given that a UK Parliament last five years, any trial must be conducted within a period not longer than two-to-three years so as to enable introduction and evaluation of the pilot. In that regard, it is not feasible to measure health outcomes themselves. Accordingly, while Kumari et al.'s study helpfully demonstrated the relationship between flatter slopes in decline of cortisol across the day and 
increased risk of cardiovascular deaths, the fact that it depended upon a six year follow-up means that trials of UBI must instead focus on measuring the physiological processes that lead to the outcomes (Kumari, et al. 2011). Put simply, a Government simply could not plan a trial outside a single Parliament, since it would be possible that, even if successful, it would be dispensed with by a successor for ideological, rather than, practical reasons.

In this political context, Webber and colleagues make a compelling case for public health modelling and its power in leveraging policy change (Webber, et al. 2014). Statistical modelling is an essential means by which to fill the evidence gap by simulating the mediumand long-term impact of interventions if scaled up to a population level. At present, the design of trials is depriving modelling of accurate data by which to scale the impacts of interventions. Modelling can perform sensitivity analysis, account for poor quality data based on qualitative assumption and provide evidence for, and inform the development of, a larger trial. However, because the trials developed thus far have not been designed with impact on health in mind, let alone to have that impact studied effectively, even the data that does exist may prove insufficient to enable scaling. It is only by designing trials with health in mind and then measuring impact on health accurately that modelling can provide us with the population level data by which to establish benefit to society as a whole and to produce the evidential basis for legislation. A Government committed to that policy would have every incentive to invest in means of measuring impact as reliably and comprehensively as possible. The measures we have outlined above take us toward a blueprint for such efforts.

Given that Hassard, et al. (2014) and Kalia (2002) both highlight the enormous impact of stress on economic activity and outcomes, such measures would enable accurate assessment of economic benefit of improved national health through introduction of UBI. This is an approach that is consistent with the UK Government's prevention agenda (Department of Health and Social Care 2019).

\section{Conclusion}

Webber and colleagues highlight the opportunity of political realignment and the need for fiscal prudence to reshape our policies to make a transformative, cumulative impact on health. If societies are to achieve this, UBI ought to be considered seriously as a means of reducing social inequalities, improving health, reducing the burden on the NHS and improving productivity.

Currently, debate has been informed by partial evidence of the social and economic benefit against what would be a very large spending commitment. The trial of guaranteed payments to unemployed people in Finland had the effect of clouding the policy debate about UBI. UBI is not only different in its structure but also has very likely population-level benefits not measured, or at least valued, in the Finnish context. Other trials have had broader objectives but provided payments in a manner that might have embedded particular forms of social hierarchy and stress that UBI generally seeks to reduce or eliminate. Where systems closer to UBI have been trialled, they have failed to measure effectively the likely mechanisms of impact on population-level health and wellbeing.

Labour's commitment to UBI at the 2019 election and interest in the policy at city- level indicates that adoption of large-scale pilots is increasingly possible. However, reporting of previous attempts and public scepticism about its feasibility mean that it is more important than ever that trials be designed appropriately. If not, potentially transformative interventions 
that meet Webber and colleagues' criteria may be overlooked in favour of less effective alternatives.

To achieve appropriate designs, collaborative work must take place between policymakers, social, political and economic theorists, epidemiologists, biomedical scientists and psychologists to ensure observation of all key factors associated with the social health gradient. To support policy development, statistical modelling must be accounted for in this design to extrapolate short- to medium-term data to long-term population-level outcomes across social strata.

This will require substantial investment of resource from Government and/or major research funders and would therefore face its own challenges. However, a comprehensive trial design is the only way that an accurate cost-benefit analysis of a UBI policy can be facilitated prior to national introduction. Indeed, such approaches should be considered for other 'upstream' interventions, given that UK Government spending on 'preventive' care in 2017 accounted for just $5 \%$ of its total health expenditure.

Without evidence of substantial economic benefit that is possible with a comprehensive trial and statistical modelling, it is unlikely that such significant interventions will be deemed viable, by government or the public. Such a project could provide a platform to pioneer this interdisciplinary approach resulting in the kind of joined-up evidence and policy that is so often sought but found just out of reach in practice.

Research ethics statement: The authors of this paper have declared that research ethics approval was not required since the paper does not present or draw directly on data/findings from empirical research.

Contributors' statement: EJ and MJ conceived and drafted this analysis. LW provided comment, feedback and specific input with regard to modelling and upstream interventions.

Conflict of interest statement: The Authors declare that there is no conflict of interest.

Acknowledgements: The authors wish to thank Daniel Nettle for his thoughtful and incisive comments on an earlier draft of this article.

\section{References}

Akee, R., Simeonova, E., Copeland, W., Angold, A. and Costello, E.J. (2013) 'Young Adult Obesity and Household Income: Effects of Unconditional Cash Transfers', American economic journal, 5(2): 1-28.

Alston, P. (2018) Statement on Visit to the United Kingdom, by Professor Philip Alston, United Nations Special Rapporteur on extreme poverty and human rights, Geneva: $\mathrm{OHCHR}$.

Brant, H., Wetherell, M.A., Lightman, S., Crown, A. and Vedhara, K. (2010) 'An exploration into physiological and self-report measures of stress in preregistration doctors at the beginning and end of a clinical rotation', Stress, 13(2), 155-162.

Chida, Y. and Steptoe, A. (2009) 'Cortisol awakening response and psychosocial factors: A systematic review and meta-analysis', Biological Psychology, 80(3): 265-278.

Cohen, S., Janicki-Deverts, D., Doyle, W.J., et al. (2012) 'Chronic stress, glucocorticoid receptor resistance, inflammation, and disease risk', Proceedings of the National Academy of Sciences, 109: 5995-5999. 
Department of Health (2012) Long Term Conditions Compendium of Information, London: Department of Health.

Department of Health and Social Care (2019) Advancing our health: prevention in the 2020s, London: Cabinet Office.

Epel, E.S., Crosswell, A.D., Mayer, S.E., et al. (2018) 'More than a feeling: A unified view of stress measurement for population science', Frontiers in Neuroendocrinology, 49: $146-169$.

Ferry J-M. (1995) LAllocation universelle pour un revenu de citoyenneté, Paris: Éd. du Cerf.

Forget, E.L. (2011) 'The Town with No Poverty: The Health Effects of a Canadian Guaranteed Annual Income Field Experiment', Canadian Public Policy, 37(3): 283305.

Gerber, M., Brand, S., Lindwall, M., et al. (2012) 'Concerns regarding hair cortisol as a biomarker of chronic stress in exercise and sport science', Journal of Sports Science and Medicine, 11(4): 571-581.

Gibson, M., Hearty, W. and Craig, P. (2018) Universal basic income: A scoping review of evidence on impacts and study characteristics, Edinburgh: What Works Scotland.

Government Digital Service. (2014) 'Universal Credit', GOV.UK, London: UK Government, https://bit.ly/10PnCw5 [Accessed 8 January 2019].

Gordon, N.J. (2014) 'The Conservative Case for a Guaranteed Basic Income', The Atlantic, 6 August, https://www.theatlantic.com/politics/archive/2014/08/why-arent-reformiconspushing-a-guaranteed-basic-income/375600.

Haagh, L. and Rohregger, B. (2019) Universal basic income policies and their potential for addressing health inequities: Transformative approaches to a healthy, prosperous life for all, Copenhagen: WHO.

Halliday, J. (2019) 'Hull asks to be first UK city to trial universal basic income', The Guardian, 19 January, https://www.theguardian.com/uk-news/2020/jan/19/hulluniversal-basic-income-trial [Accessed 27 January 2020].

Hassard, J., Teoh, K., Cox, T., et al. (2014) Calculating the cost of work-related stress and psychosocial risks: European Risk Observatory Literature Review, Luxemburg: European Agency for Safety and Health at Work.

Haushofer, J. and Shapiro, J. (2016) 'The Short-term Impact of Unconditional Cash Transfers to the Poor: Experimental Evidence from Kenya', The Quarterly Journal of Economics, 131: 1973-2042.

Haushofer, J. and Shapiro, J. (2018) The long-term impact of unconditional cash transfers: experimental evidence from Kenya, https://bit.ly/2zTB4pg.

Health and Safety Executive (2016) Work related Stress, Anxiety and Depression Statistics in Great Britain, 2016, London: Health and Safety Executive.

Health and Safety Executive (2018) Work related Stress, Anxiety and Depression Statistics in Great Britain, 2018, London: Health and Safety Executive.

Henderson, B.N. and Baum, A. (2004) 'Biological mechanisms of health and disease', in S. Sutton, A. Baum and M. Johnston (eds), The Sage handbook of health psychology, London: Sage. pp 69-93.

Henley, J. (2018) 'Finland to end basic income trial after two years', The Guardian, 23 April, https://www.theguardian.com/world/2018/apr/23/finland-to-end-basic-income-trialafter-two-years [Accessed 27 January 2020].

Henley, J. and agencies (2019) 'Finland's "free cash" experiment fails to boost employment', The Guardian, 8 February, https://www.theguardian.com/world/2019/feb/08/finlandfree-cash-experiment-fails-to-boost-employment [Accessed 27 January 2020].

Johnson, E.A., Spring, E. (2018) The Activity Trap: Disabled people's fear of being active, Manchester: Activity Alliance. 
Johnson, M.T. and Johnson, E.A. (2019) 'Stress, Domination and Basic Income: Considering a citizens' entitlement response to a public health crisis', Social Theory \& Health, 17(2): 253-271.

Johnson, M.T., Geyer, R., Degerman, D. (2019) 'Exploring the health case for a trial of Universal Basic Income: Evidence from GPs working with the long-term unemployed', Basic Income Studies, 14:2, 1-11, 20190008. DOI:10.1515/bis-20190008 .

Kalia, M. (2002) 'Assessing the Economic Impact of Stress: The Modern Day Hidden Epidemic', Metabolism, 51(6): pp 49-53.

Kangas, O., Jauhiainen, S., Simanainen, M., Ylikännö, M. (2019) The basic income experiment 2017-2018 in Finland: Preliminary results, Helsinki: The Ministry of Social Affairs.

Kehrer, B.H. and Wolin, C.M. (1979) 'Impact of income-maintenance on low birth-weight evidence from the Gary experiment', Journal of Human Resources, 14(4): 434-462.

Kumari, M., Shipley, M., Stafford, M., Kivimaki, M. (2011) 'Association of Diurnal Patterns in Salivary Cortisol with All-Cause and Cardiovascular Mortality: Findings from the Whitehall II Study', The Journal of Clinical Endocrinology and Metabolism, 96: $1478-1485$.

Labour Party (2019) It's Time for Real Change: The Labour Party Manifesto 2019, London: The Labour Party.

Lombardo, P., Jones, W., Wang, L., et al. (2018) 'The fundamental association between mental health and life satisfaction: results from successive waves of a Canadian national survey', BMC Public Health, 18(1): https://doi.org/10.1186/s12889-018$\underline{5235-\mathrm{X}}$.

Marmot, M.G. and Steptoe, A. (2008) 'Whitehall II and ELSA', in M. Weinstein, J. W. Vaupel and K. W. Wachter (eds), Biosocial surveys, Washington: National Academies Press. pp 42-59.

Office for National Statistics (2019) Healthcare expenditure, UK Health Accounts: 2017, https://www.ons.gov.uk/peoplepopulationandcommunity/healthandsocialcare/healthca resystem/bulletins/ukhealthaccounts/2017 [Accessed: 28 January 2020].

Painter, A. (2016) 'A universal basic income: the answer to poverty, insecurity, and health inequality?', BMJ, 355: i6473.

Pettit, P. (2008) 'A Republican Right to Basic Income?', Basic Income Studies, 2(2): https://doi.org/10.2202/1932-0183.1082.

Pohjanpalo, P. (2019) 'Free Money Didn’t Help People Find Jobs, Finland Says', Bloomberg.com, 8 February, https:/www.bloomberg.com/news/articles/2019-0208/finland-finds-basic-income-failed-to-boost-employment [Accessed 27 January 2020].

Press Association (2019) 'Labour would trial universal basic income if elected, John McDonnell says', The Guardian, 12 May, https://www.theguardian.com/society/2019/may/12/labour-would-trial-universalbasic-income-if-elected-john-mcdonnell-says [Accessed 18 May 2019].

Psychologists for Social Change (2017) Universal Basic Income: A Psychological Impact Assessment, London: PAA.

Richardson, E., Fenton, L., McCartney, G., et al. (2018) Income-based policies in Scotland: how would they affect health and health inequalities?, Edinburgh: NHS Health Scotland.

Sheahan, A. (2003) Basic income guarantee: Your right to economic security, Basingstoke: Palgrave Macmillan. 
Simpson, E.E.A., McConville, C., Rae, G., et al. (2008) 'Salivary cortisol, stress and mood in healthy older adults: The Zenith study', Biological Psychology, 78(1): 1-9.

Smith, S.M. and Vale, W.W. (2006) 'The role of the hypothalamic-pituitary-adrenal axis in neuroendocrine responses to stress', Dialogues in Clinical Neuroscience, 8(4): 383395.

Standing, G. (2019) Basic Income as Common Dividends: Piloting a Transformative Policy: A Report for the Shadow Chancellor of the Exchequer, London: Progressive Economic Forum, https://www.progressiveeconomyforum.com/wpcontent/uploads/2019/05/PEF Piloting Basic Income Guy Standing.pdf.

Tang, K.L., Rashid, R., Godley, J. and Ghali, W.A. (2016) 'Association between subjective social status and cardiovascular disease and cardiovascular risk factors: a systematic review and meta-analysis', BMJ Open, 6:e010137.

Valero, J. (2019) 'Finnish finance minister: 'Case closed' for universal basic income', www.euractiv.com, 12 February, https://www.euractiv.com/section/economyjobs/interview/finnish-finance-minister-case-closed-for-universal-basic-income/ [Accessed 27 January 2020].

Webber, L., Chalkidou, K., Morrow, et al. (2018) 'What are the best societal investments for improving people's health?', $B M J, 362$ : k3377.

Webber, L., Mytton, O.T., Briggs, A.D., et al. (2014) 'The Brighton declaration: the value of non-communicable disease modelling in population health sciences', European Journal of Epidemiology, 29: 867-870. 